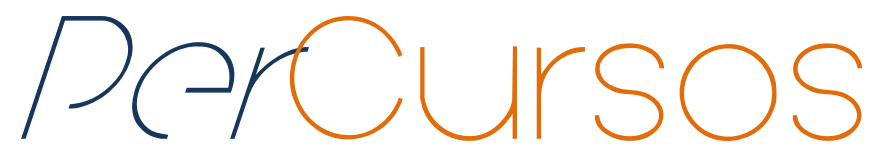

\title{
Conflitos socioambientais na construção de hidrelétricas e os dilemas da produção energética: o caso de Três Gargantas (China)
}

\begin{abstract}
Resumo
Este artigo apresenta uma revisão bibliográfica sobre a construção da Hidrelétrica de Três Gargantas, buscando elencar os principais elementos motivadores de conflitos ambientais, sociais, econômicos e políticos, além de reconhecer o dilema existente sobre produção energética. Projetada para minimizar as inundações do Rio Yangtze e garantir elevada produção de energia, a hidrelétrica impactou extensa região da China, deslocando alto número de moradores e evidenciando uma série de disputas e conflitos. Sua construção ocorreu durante a década de 1990, alterou o ecossistema local e regional, inundou diversas cidades, destruiu sítios arqueológicos. Houve fraca participação da sociedade civil durante o projeto de implantação, em virtude da presença de um Estado centralizador, que não permitiu a expressão da população. Tal fato intensifica a presença de conflitos latentes e potenciais, que ainda perduram apesar do passar dos anos. A reflexão sobre essa experiência local pode suscitar questões para se pensar globalmente acerca das construções com grande impacto ambiental, e suas repercussões nas diversas esferas sociais, ecológicas e políticas.
\end{abstract}

Palavras-chave: China. Hidrelétricas - Três Gargantas. Impacto Ambiental. Bem-estar Social.

\author{
Mariana Delgado Barbieri \\ Mestre em Sociologia pela \\ Universidade Estadual de \\ Campinas - UNICAMP.
}

Doutoranda em Ambiente e

Sociedade na Universidade

Estadual de Campinas -

UNICAMP.

Brasil

marianabarb@yahoo.com

\footnotetext{
Para citar este artigo:

BARBIERI, Mariana Delgado. Conflitos socioambientais na construção de hidrelétricas e os dilemas da produção energética: o caso de Três Gargantas (China). Revista PerCursos, Florianópolis, v. 19, n.41, p. 28 49, set./dez. 2018.
}

DOI: $10.5965 / 1984724619412018028$

http://dx.doi.org/10.5965/1984724619412018028 


\title{
Socio-environmental conflicts in the construction of hydroeletric dams and the dilemas of energy production: The Three Gorges case (China)
}

\begin{abstract}
The article presents a bibliographical review on the construction of The Three Gorges Dam, seeking to list the main motivating elements of environmental, social, economic and political conflicts, as well as to recognize the existing dilemma about energy production. Designed to minimize the flooding of the Yangtze River and to ensure high energy production, the hydroelectric dam has impacted a huge region of China, displacing many residents and highlighting a series of disputes and conflicts. Its construction took place during the 1990s, altering the local and regional ecosystem, flooding several cities and destroying archaeological sites. There was a weak participation of civil society during the implantation project, mostly due to the presence of a centralizing State, which did not allow the expression of its population. This fact intensifies the presence of latent and potential conflicts, which persist despite the passage of the years. The reflection about this local experience can raise questions to think globally about constructions with great environmental impact, and their repercussions in the diverse social, ecological and political spheres.
\end{abstract}

Keywords: Three Gorges Hydroelectric Plant. SocioEnvironmental Conflicts. Social welfare. 
O presente artigo versa sobre a Hidrelétrica das Três Gargantas, localizada na China. Motivadora de debates e conflitos, a construção é símbolo do poderio chinês que busca continuar crescendo economicamente e, para isso, necessita de novas formas para atender o aumento da demanda energética. $O$ artigo busca, a partir de um caso específico - a experiência chinesa -, fornecer elementos descritivos capazes de permitir a reflexão acerca das construções de hidrelétricas. O que foi vivenciado na China pode servir de exemplo para outras localidades.

Para melhor compreensão da temática, apresentaremos um panorama dos principais aspectos envolvidos na obra, iniciando com uma contextualização do momento histórico, da questão ambiental e energética, dados do projeto, impactos ambientais e sociais, conflitos resultantes da instalação e atuação da população local e movimentos sociais, buscando elementos aptos a problematizarem as diversas esferas envolvidas nos projetos de hidrelétricas.

O artigo faz uma revisão bibliográfica sobre o tema, utilizando-se de fontes secundárias, e intenta contribuir com a discussão científica a respeito dos grandes empreendimentos e seus impactos nas esferas ambientais, sociais, econômicas, identificando os conflitos ambientais latentes, atores envolvidos e formas de negociação. Este artigo é fruto de pesquisas desenvolvidas nos projetos "O desafio das mudanças ambientais globais no Antropoceno: ênfase nas questões das dimensões humanas das mudanças climáticas (Brasil, China e Moçambique)" (FAPESP 2017/06347-3) e "Sociedade Civil, Estado e questão ambiental na China Contemporânea" (CAPES).

\section{Modernização, crescimento e questão ambiental}

A política de modernização e desenvolvimento da China, comandada por Deng Xiaoping no final da década de 1970, foi a responsável pelo grande avanço econômico, social e industrial das décadas de 1990 e 2000 que surpreenderam o mundo.

O chamado Plano das Quatro Modernizações, que entrou em vigor em 1978, previa o desenvolvimento de quatro áreas especificas: agricultura, ciência e tecnologia, indústria e forças armadas. Após décadas de desastres políticos e sociais, a China começava um 
novo momento histórico de abertura para o mundo e de consciência de suas potencialidades. Os planos quinquenais elaborados pelo Partido Comunista Chinês traçaram metas a serem alcançadas em curto, médio e longo prazos (POMAR, 2003).

O poderio econômico e o papel de superpotência consolidado ao longo dos anos 2000 demonstram que o Plano das Quatro Modernizações está alcançando seus objetivos, promovendo profundas mudanças na organização social chinesa, com forte deslocamento da população do campo para as cidades, incremento e diversificação das indústrias, grande crescimento no PIB e melhoria nos índices sociais (SPENCER, 1995).

O crescimento econômico chinês veio acompanhado do adensamento populacional e do aumento no consumo energético, gerando consequente aumento vertiginoso da poluição e emissão de GEE (gases de efeito estufa) e atuando diretamente nas atuais mudanças climáticas sentidas em todo o mundo (FERREIRA, 2017). Dados indicam que a China, em 2008, era responsável por 23\% da emissão mundial de GEE, com crescimento de $5 \%$ ao ano, sendo então considerada uma potência climática, que juntamente com EUA e Rússia contribuem com 60\% das emissões de GEE (VIOLA, 2010). O aumento da queima de carvão, principal matriz energética da China, contribui diretamente com o aumento da poluição e eleva os índices de gases tóxicos e material particulado, afetando localmente a saúde da população, e contribuindo globalmente com as mudanças ambientais e climáticas (IPCC, 2007; IPCC, 2013).

No atual contexto de sociedade global, as mudanças ambientais não mais são vistas como fenômenos isolados ou locais, mas sim atingem indistintamente todas as populações do globo, ocasionando inundações, secas, alto índice de poluição atmosférica, contaminação do solo e da água, redução da diversidade animal e vegetal, desertificação (BECK, 2010; GIDDENS, 2010; FERREIRA; BARBI, 2012). Dentre as mudanças ambientais, a que possui maior destaque é a mudança climática, conforme afirma Beck:

A mudança climática é a dimensão mais urgente, mais grave e mais profunda da crise ambiental do século XXI. É urgente porque resta pouco tempo para estabilizar a concentração de gases de efeito estufa em níveis aceitáveis na atmosfera. É grave porque aumenta significativamente a desertificação, a crise de recursos hídricos e a crise 
de biodiversidade. Além disso, destrói muita infraestrutura existente, traz grandes prejuízos às atividades econômicas e afeta com severidade as populações pobres do planeta. E é profunda porque não existe solução apenas tecnológica. (BECK, 2010, p. 10)

A complexidade dos riscos, a abrangência global, sua permeabilidade por toda a sociedade, transformam a questão da mudança climática em um dos temas fundamentais do século XXI (BECK, 2010; GIDDENS, 2010). Essa preocupação fez com que o chamado Intergovernmental Panel on Climate Change (IPCC), criado em conjunto pela Organização das Nações Unidas (ONU) e pela Organização Meteorológica Mundial (WMO), reunissem esforços para compreender o fundamento do sistema climático global, e os últimos relatórios indicam que a ação humana é a maior responsável pelo aquecimento global nos últimos cinquenta anos.

O aumento da temperatura na superfície terrestre traz inúmeras consequências ao globo: aumento de tufões e secas, extinção de espécies, elevação da temperatura dos oceanos, derretimento das camadas polares e consequente elevação dos oceanos - o que causa o desaparecimento de ilhas e obriga centenas de pessoas a se transformarem em refugiados ambientais, pessoas obrigadas a deixar o local de habitação em virtude das alterações ambientais (IPCC, 2013).

Consequentemente, como resposta à necessidade de conter o avanço das emissões de GEE, buscando controlar o aumento da temperatura na superfície terrestre, a atuação dos governos é elemento fundamental. A constituição de uma governança preocupada com a questão ambiental é primordial para o controle dos riscos. Reconhecendo tal importância, acordos como o de Copenhague ou o Tratado de Kyoto buscam apresentar metas a serem cumpridas pelos governos, entretanto, ainda enfrentam uma efetividade limitada (VIOLA, 2010).

Nesse contexto, os riscos, apesar de serem invisíveis e escaparem da percepção humana num primeiro momento, se tornam reconhecidos quando se constrói um conhecimento sobre eles. Nesse sentido, “o monopólio da verdade do juízo científico obriga assim que os próprios afetados façam uso de todos os meios e métodos da análise 
científica para implementar suas demandas. E obriga ademais que eles ao mesmo tempo os modifiquem" (BECK, 2010, p. 87).

\section{A questão energética}

A questão energética é um dos pontos principais para se garantir a continuidade do crescimento chinês que, entretanto, é a principal responsável pela intensificação das mudanças climáticas. No início dos anos 2000, por decorrência de constantes apagões que paravam as indústrias por vários dias ao longo do ano, impactando na produção de bens, milhões de dólares deixaram de ser produzidos. Responder adequadamente ao aumento da demanda energética passou a ter um significado de segurança econômica e nacional.

Para lidar com esse aumento significativo na demanda por energia, e, juntamente com a pressão internacional, o governo propôs um plano de diversificação energética aprovado em 2006 - o XI Plano Energético, como maneira de suprir o aumento da demanda sem que para isso fosse necessária uma quantidade ainda maior de carvão. Foi desenvolvido concomitantemente ao XI Plano Quinquenal (2006-2010), no qual o governo demonstrou preocupações com o a qualidade de vida da população e a proteção ao meio ambiente. Essa foi a primeira vez que a questão apareceu claramente em um plano quinquenal (LIMA, 2007; BASSO; VIOLA, 2014).

A queima de combustíveis fósseis corresponde a 90\% do total de emissão de carbono, e a geração de energia e a manufatura é responsável por $85 \%$ das emissões de GEE (gases de efeito estufa) (LIU, 2015). A preocupação em desenvolver fontes alternativas está diretamente relacionada com a necessidade de se reduzir o volume de emissões, que apresenta a maior taxa do mundo, ainda que a emissão per capita seja menor do que a de vários países (LIU, 2015).

As usinas termelétricas a carvão são as grandes responsáveis pela poluição no país, e o desenvolvimento de fontes renováveis busca, a princípio, suprir a demanda adicional vinculada ao crescimento econômico, paulatinamente substituindo as antigas usinas termelétricas. As energias eólica e solar são as grandes apostas do governo chinês, 
que tem apoiado amplamente as pesquisas nessa área, para que se chegue em 2020 com $15 \%$ da produção energética baseada em fontes limpas. A China vem investindo fortemente em tecnologia e na busca de melhor eficiência energética, além de fortalecer o controle da poluição. O que se busca é diversificar a matriz energética, diminuindo a dependência do carvão mineral (VEIGA et al., 2015; FERREIRA; BARBI; D'OTAVIANNO, 2016).

O desenvolvimento de uma economia de baixo carbono, que visa suprir as necessidades da população, mas sem comprometer o futuro, reduzindo drasticamente os riscos ecológicos e ambientais (BASSO; VIOLA, 2014), é o grande desafio chinês para o século XXI. Para isso, é preciso reduzir as emissões de carbono, mantendo o crescimento econômico mas com o menor impacto ambiental e menor alteração climática possível. 0 que se busca é um equilíbrio no tripé energia-economia-clima. Esse equilíbrio é a base da chamada civilização ecológica, projeto de sociedade idealizado por Xi Jinping, a partir do $13^{\circ}$ Plano Quinquenal, divulgado em 2015 (CHINA, 2015).

O projeto de instalação da Hidrelétrica das Três Gargantas remete ao final da década de 1980, quando as primeiras preocupações com a questão ambiental começavam a surgir, num momento de crescimento da demanda energética e de busca por produção alternativa de energia, ainda que o reconhecimento da necessidade de se reduzir a emissão de GEE não tenha sido um fator de motivação para o projeto. Com a construção completa da hidrelétrica em 2013, a China tornou-se o maior produtor mundial de hidroeletricidade, com produção anual de $280 \mathrm{MW}$, mais de um quinto da capacidade total de geração (VEIGA et al., 2015).

\section{A Hidrelétrica de Três Gargantas}

A maior obra de engenharia já feita em todo mundo, construída ao longo do Rio Yangtze, foi proposta inicialmente por Sun Yat-Sen, em 1919. Mais tarde, durante a década de 1950, após a morte de milhares de pessoas vítimas das inundações do rio, Mao Zedong revisitou a proposta, com o intuito de controlar as inundações e produzir energia 
nas águas do Yangtze, entretanto disputas políticas, questões econômicas e debates técnicos impediram o andamento do projeto (LIANG, 2010).

O Rio Yangtze é o terceiro maior rio do mundo e o maior da Ásia. Percorre 6.300 km e sua bacia hidrográfica é responsável por irrigar as terras férteis da China, conforme apresenta a figura 1. Possui grande importância no desenvolvimento histórico, econômico e cultural da China, sendo uma barreira física que separa as regiões culturais da China, Norte e Sul. Em suas águas, são transportadas cerca de 18 milhões de toneladas de mercadorias por ano, matérias-primas e produtos agrícolas, em numerosos navios - cerca de 170 navios por dia navegam nas águas do Yangtze. Na região das Três Gargantas, há indícios de vida humana datados de 27 mil anos (MAHER, 2010).

Figura 1 - Rio Yangtze e Hidrelétrica das Três Gargantas (WATSON, 2008)

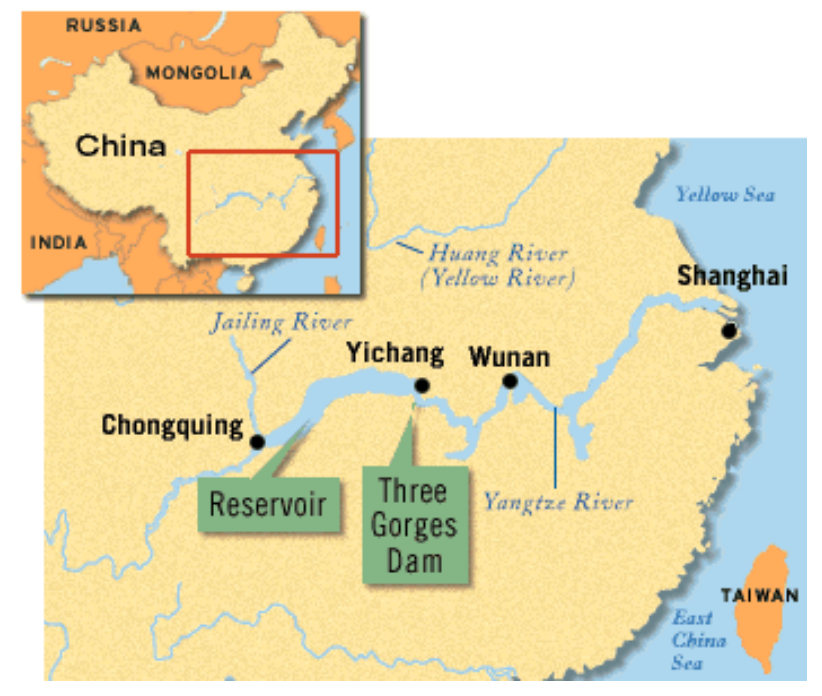

O plano de construção de barragem na região volta à pauta governamental em 1986, quando se identificou o descompasso entre o crescimento econômico e a geração de energia. Em 1988, Li Peng assume o cargo de Primeiro-Ministro e decide investir na construção da hidrelétrica. Li Peng, engenheiro treinado na URSS, com carreira na área de geração de energia por hidrelétricas, passa a ser o maior incentivador do projeto. Importante frisar que desde a fundação da República Popular da China, em 1949, a relação que se estabelece com a natureza é de dominação; os ideais comunistas 
defendidos por Mao Zedong pregavam que a natureza deveria ser controlada e o sucesso na construção de um projeto com tal grandiosidade seria uma grande prova do poderio do Partido Comunista Chinês (BEATTIE, 2002).

Com a criação do consórcio CIPM Yangtze Joint Venture, que firmou parceria com três companhias privadas e duas empresas estatais do Canadá, o projeto foi aprovado oficialmente pelo congresso nacional em 1992, iniciando as obras em 1994. Em 2003, teve início a geração de energia, e a obra foi finalizada em 2006 (LIANG, 2010). Com mais de 200 metros de altura, a obra possui um reservatório com mais de 600 quilômetros de extensão e capacidade de armazenamento de 40 bilhões de metros cúbicos. Com 26 turbinas geradoras instaladas, alcançou a produção de 98,8 milhões de $M W / h$, superando a marca de Itaipu (LIANG, 2010).

Para além da produção de energia, a construção da barragem objetivou reduzir o número de inundações e possibilitar a navegação ao longo de centenas de quilômetros do rio. Uma obra com essas dimensões, com custo estimado de 30 bilhões de dólares, é evidentemente responsável por uma série de impactos sociais, ambientais, políticos e econômicos. O debate acerca da instalação da hidrelétrica gerou diversas análises ao redor do mundo, em que se propôs evidenciar os aspectos positivos e negativos da obra.

\section{Impactos ambientais}

São diversos os impactos ambientais e ecológicos produzidos a partir do início da construção da barragem. O primeiro e mais previsível diz respeito à pesca e à diversidade dos peixes, diretamente influenciadas pelas transformações no leito do rio, com alteração na dinâmica dos fluxos de água, composição química, temperatura, mudança no habitat natural e na disponibilidade de alimentação. Essas transformações afetaram diretamente as populações de peixes, extinguindo algumas espécies e reduzindo em até 70\% o volume da pesca em determinadas regiões. Para além do impacto ambiental, produziu-se um impacto social e econômico, afinal, muitas famílias dependiam da pesca para a sua sobrevivência (GLEICK, 2009). 
As alterações no ecossistema afetaram outras espécies, como o boto-do-índico, e provocaram desequilíbrios, com o aumento no número de doenças, como a esquistossomose. Alterações na flora e na vegetação ciliar também ocorreram, dizimando espécies endêmicas.

A alteração no fluxo do rio e a incapacidade de administrar o seu volume em níveis constantes, ocasionam secas na área de rio abaixo da usina, deixando grandes cidades sem água potável (YANG; LU, 2013).

Além disso, presença de alto volume de sedimentos, que ficam acumulados na parte anterior à barragem pode ocasionar sérios problemas. O grande acúmulo pode aumentar o nível do rio, provocar inundações, e num cenário extremo, destruir a barragem. Ademais, o acúmulo de sedimentos somado à poluição altera profundamente o equilíbrio ecológico de toda a região, que corresponde a mais de $35 \%$ do território chinês (YANG; LU, 2013).

Outro impacto importante foi o aumento dos riscos geológicos na região das Três Gargantas. Isso ocorre em virtude das flutuações no nível da água, que causam sismos e erosões nas margens do rio. Grandes reservatórios de água são capazes de provocar eventos sísmicos significativos, pois o grande volume de água provoca pressão em falhas geológicas já existentes. Subestimado, o impacto geológico foi reconhecido por autoridades chinesas em 2011, e alguns cientistas afirmam que o peso do reservatório das Três Gargantas foi o fator motivador para o terremoto que ocorreu em maio de 2008, na província de Sichuan, e matou mais de 80 mil pessoas (WINES, 2011).

Novos estudos vêm demonstrando que a Hidrelétrica, por sua magnitude, está alterando as características climáticas locais e mudando índices médios de temperatura e precipitações. Essas alterações extrapolam as previsões originais, mas ainda é preciso fazer mais pesquisas para compreender a dinâmica do processo (GLEICK, 2009). Apesar de todas essas consequências, para defensores do projeto, a destruição da natureza é um custo necessário e inevitável para o desenvolvimento econômico (BEATTIE, 2002).

Esses impactos ambientais podem ser diretamente relacionados à noção de risco derivado do meio ambiente criado, de Anthony Giddens, que defende que a transformação 
da natureza a partir dos sistemas de conhecimentos humanos é potencial geradora de riscos, ao intervir na natureza e produzir um ambiente de risco (GIDDENS, 1991). São riscos de natureza antrópica, derivados de intervenções e obras, e um grande problema é a incapacidade dos sistemas peritos em avaliarem e reconhecerem os efetivos riscos existentes. Tais riscos são consequências da modernidade, e ilustram perfeitamente a ideia de Beck de que "viver na 'sociedade de risco' significa viver em circunstâncias incertas criadas por nós mesmos" (DAVID, 2011, p. 31).

\section{Impactos sociais}

Um dos aspectos mais devastadores do projeto das Três Gargantas, reconhecido em estudos feitos pela Academia Chinesa de Ciências, trata do remanejamento das populações que vivem nas áreas próximas aos rios. Os números reais são assustadores: entre 1,3 e 2 milhões de pessoas tiveram que se deslocar da área; ficaram submersas 13 cidades, 140 vilas e 1300 vilarejos; mais de 1300 indústrias estão localizadas na área submersa, o que pode provocar despejo de resíduos tóxicos e outros materiais contaminantes; mais de 360 milhões de pessoas moram nos arredores da área e podem ser diretamente prejudicadas pelos riscos que a hidrelétrica produz (MAHER, 2010).

A região também possui mais de 100 sítios arqueológicos, com objetos datados com mais de 20.000 anos. Berço da etnia Ba, que foi dizimada pela dinastia Qing, há vasto material de pesquisa arqueológica. Importantes templos, como Shibaozhai e Zhang Fei, e esculturas de mais de 500 anos também foram submersas, além de tumbas e monumentos feitos entre 25 e 200 d.C. (MAHER, 2010). Cidades como Fuling e Wanxian possuíam mais de 1000 anos de existência e hoje estão embaixo d'água (GLEICK, 2009). Apesar do inegável valor histórico da região, antes do alagamento da área não foi realizado nenhum trabalho aprofundado que tentasse remover ou catalogar todas essas preciosidades que fazem parte da história da humanidade.

O deslocamento e reassentamento da população trouxe um alto custo ao governo. Calcula-se que já tenham sido investidos em torno de 15 bilhões de dólares no remanejamento da população, entretanto, os problemas enfrentados são vários: falta de 
infraestrutura nas cidades que passaram a abrigar essa população realocada, falta de empregos, alteração dos meios tradicionais de cultivo, baixíssima indenização, ausência de consulta pública precedente à tomada de decisões. Uma série de dificuldades advém da instalação da hidrelétrica, e todo o processo de construção e alteração da vida da população local faz surgir conflitos nessa área.

Além da necessidade de deslocamento da população, existe a questão da indenização dessas famílias. Na China, não existe propriedade privada de terras, logo as famílias que vivem nas regiões rurais não são donas dos terrenos, mas sim têm autorização de uso pelo governo. Logo, a indenização que o governo oferece é uma baixa quantia em moeda e um local para nova instalação da família. Estudos feitos na região mostram que as famílias realocadas tiveram queda na qualidade de vida e nas condições econômicas, visto que muitas receberam terrenos impróprios para agricultura e menos favoráveis à exploração. Além disso, famílias enfrentam o desemprego nas novas cidades e a falta de uma estrutura adequada para receber os novos moradores.

\section{Conflitos na região do Yangtze}

As partes envolvidas no conflito resultante da construção da Hidrelétrica de Três Gargantas são várias: agricultores locais, moradores expulsos dos vilarejos e cidades, defensores dos direitos humanos, ambientalistas contrários à construção, arqueólogos, moradores das cidades que receberam os reassentados, o governo chinês e seus funcionários locais, ambientalistas favoráveis à construção. Esses são os atores principais do conflito, mas ainda é possível reconhecer outros, como membros de entidades internacionais, cientistas e analistas, que a partir de suas conclusões sobre a construção influenciam diretamente na estrutura do conflito (WATSON, 2008).

Uma das maiores obras da humanidade e a mais significativa alteração na paisagem natural do mundo, levou milhões de pessoas à situação de vulnerabilidade social, ao impor o deslocamento dessa população, obrigada a abandonar suas raízes culturais e sociais, a partir de uma imposição do governo. A construção da hidrelétrica foi 
um processo decisório centralizado no Estado, sem que houvesse a participação popular na tomada de decisão.

Fundamental contextualizar o momento histórico em que os fatos se desenvolvem. Em 1989, tivemos o Massacre na praça da paz celestial (Tian'anmen), quando o governo reprimiu violentamente as manifestações pacíficas promovidas principalmente pelos jovens e intelectuais que contestavam a repressão por parte do Partido Comunista Chinês. Após o episódio, passou a haver grande dificuldade em expressões políticas contrárias ao governo, num retrocesso frente aos avanços obtidos ao longo dos anos de 1980, que paulatinamente havia permitido alguma liberdade de expressão e contraposição ao Partido (LULL, 1992; SPENCER, 1995). A aprovação das obras das Três Gargantas ocorre nesse cenário, o que reprime a demonstração de reprovação por parte dos diversos atores sociais, numa completa ausência de diálogo entre governo e população.

Para evitar a contestação do projeto, o governo fez um trabalho de divulgação em que frisava a necessidade de construção da hidrelétrica por alguns motivos: suprir a demanda de energia, substituir a queima de carvão por uma energia mais limpa e solucionar os problemas de inundações na área. A aprovação do projeto visava ser uma resposta às pressões internacionais pela redução do uso de combustíveis fósseis, e era uma questão de soberania nacional e de manutenção do crescimento econômico. Ir contra o projeto configuraria uma atitude antinacionalista e que acarretaria repressão pelo Partido (LIN, 2007).

O que se verifica, conforme argumenta Raquel Teixeira (2005), é uma noção de conflito que surge pela interação entre as populações atingidas e o governo:

já que não há um processo de negociação, livre comunicação e construção de consensos, ao contrário, trata-se do embate entre segmentos sociais que articulam interesses, posicionamentos e visões opostas no interior de um espaço social assimetricamente estruturado. (TEIXEIRA, 2005, p. 17) 
É possível compreendermos o conflito que se institui com o projeto, a partir de duas bases que se interligam: aspectos sociais e aspectos ambientais. O que perpassa esses elementos é a chamada violência estrutural, que, diferentemente da violência física, não é facilmente identificada. Winter e Leighton (2001) explicam que a violência estrutural é na maioria das vezes invisível, infiltrada nas diversas estruturas sociais, normatizada pelas instituições e ocorre principalmente entre indivíduos que estão em desvantagem política, legal, econômica ou cultural. Essa violência estrutural pode provocar violência direta, após alcançar situações limites, quando não há negociações entre as partes envolvidas.

Quando um grande número de pessoas é obrigado a deixar suas casas, a partir de coação por parte do governo, sujeitas à situação de pobreza e de queda brutal de seu nível de vida, temos presente a violência estrutural, silenciosa. O esquema abaixo (figura 2), desenvolvido por Blake Campbell-Hyde (2011), facilita a visualização do potencial conflito. A partir dos impactos ambientais e sociais, é possível que ocorra um conflito violento na região; afinal a instabilidade social e ambiental é detentora de estímulos que promovem o descontentamento extremo da população. Mas, frisamos, o conflito latente já existe. 
Figura 2 - Esquematização do conflito na região (Campbell-Hyde, 2011)

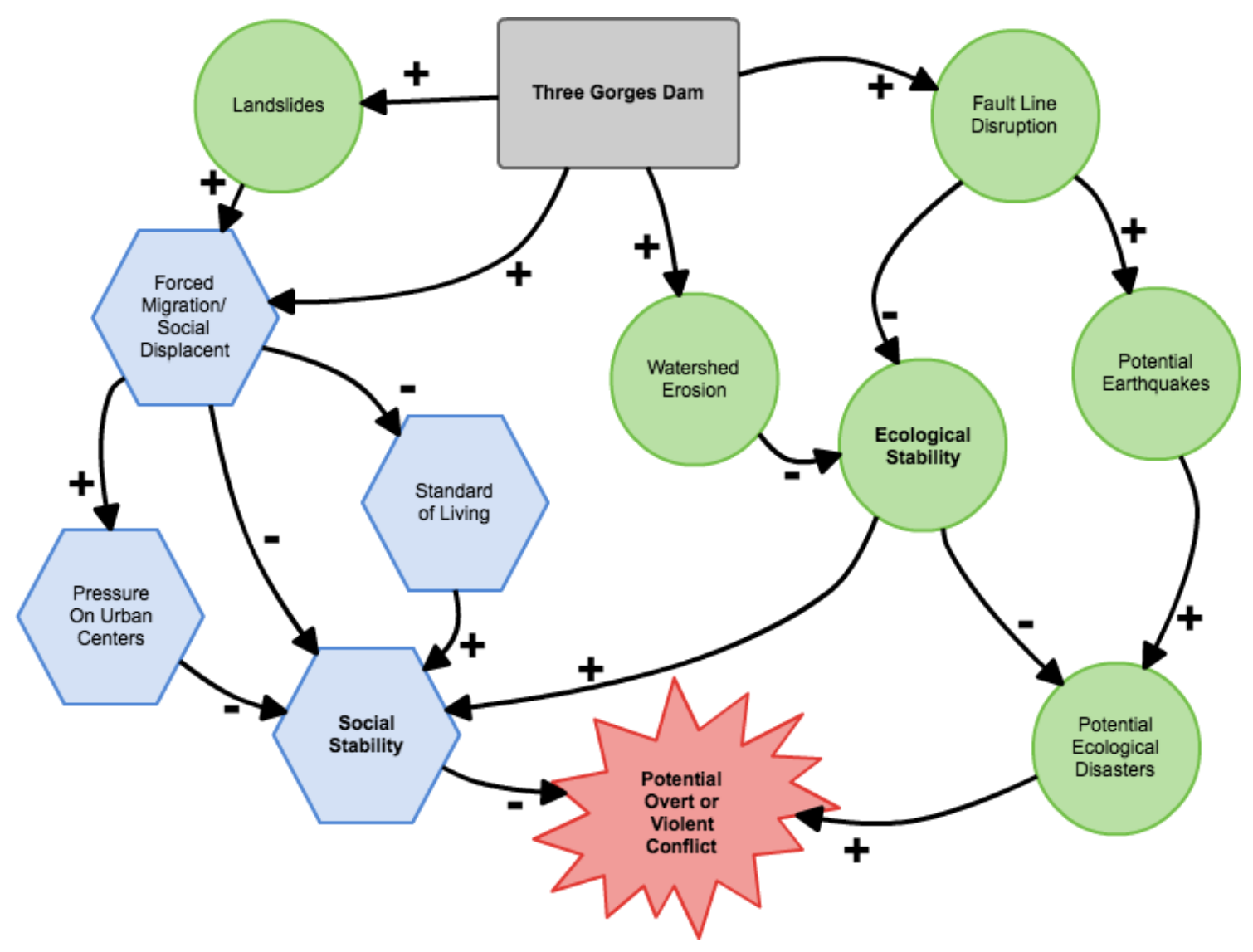

Poderia ser acrescentada a esse esquema a violação dos direitos humanos, item denunciado internacionalmente por diversas organizações, principalmente pela violação dos direitos dos moradores locais, remanejados sem garantia de cumprimento da proposta governamental de indenização. Relatos mostram que muitos moradores receberam menos de 7 dólares por mês como indenização, valor insuficiente para garantir sequer alimentação. Outro aspecto de violação dos direitos humanos refere-se à supressão de qualquer opinião contrária ao projeto, conforme já sinalizado. Um projeto com tal dimensão foi efetivado de maneira autoritária (INTERNATIONAL RIVERS NETWORK, 2003).

Esse panorama nos permite captar a dimensão do conflito em suas várias arestas, seja pela luta pelo uso dos recursos naturais, a luta política pelos direitos humanos ou a luta que visa diminuir os impactos sociais e econômicos. O conflito já dura ao menos 30 anos, desde quando foi anunciada a sua construção. A tendência ainda é de que dure 
muito mais, visto que mesmo que se solucionem as questões de reassentamento, os riscos ambientais podem se intensificar, atingindo um altíssimo número de pessoas, caso haja novos terremotos ou, até mesmo, caso haja o rompimento da barragem e alagamento de grandes áreas. O que pode ocorrer é a transformação do conflito, mas não o seu desaparecimento.

Apesar de tantos impactos negativos, frutos da construção da hidrelétrica, é possível compreender o conflito na localidade como um elemento positivo para o desenvolvimento de atores e ações sociais. Conforme afirma Simmel, "Admite-se que o conflito produza ou modifique grupos de interesse, uniões, organizações [...] é uma forma de sociação" (SIMMEL, 1983, p. 122). As interações que ocorrem motivadas pelo conflito levam à constituição de grupos de interesses que se transformam em atores sociais, sendo o conflito um ato do reconhecimento das partes díspares (ALCÂNTARA JUNIOR, 2005). O conflito gera sociações potencialmente transformadoras, ao possibilitar a mudança da realidade social existente. Decorrente dessa possibilidade de transformação, o conflito deve ser visto como dotado de aspectos positivos, sendo um elemento fundamental para a estrutura social, suas readequações e dinâmicas.

No caso da Hidrelétrica das Três Gargantas, temos diversos movimentos e atores sociais surgindo como consequência direta do conflito, buscando intervir, garantir direitos, posicionando-se ao lado da população local, que deixa de estar sozinha na luta e na superação dos impactos decorrentes do projeto.

\section{Participação pública}

Em 1989, Dai Qing, uma jornalista chinesa, reuniu uma série de entrevistas e artigos sobre o projeto da hidrelétrica. Apresentava estudos das consequências catastróficas do projeto e seus impactos sociais, econômicos, ambientais e políticos, posicionando-se num forte embate com as decisões governamentais. Após o episódio de Tian-anmen, o livro Yangtze! Yangtze! foi proibido de circular na China e a autora foi presa diversas vezes. Com apoio de entidades internacionais, o livro foi publicado no exterior, e o impasse passou a ser conhecido internacionalmente. A própria autora afirmava que o 
livro não se engajava no ambientalismo, mas defendia a liberdade de expressão perante a tomada de decisão do governo (BEATTIE, 2002).

Conforme defende Teh-Chang Lin (2007), a incapacidade do Estado em lidar com as vozes da oposição e em garantir princípios democráticos e direitos humanos já consagrados no Ocidente, fez surgir uma agitação social entre camadas da população descontentes com a situação. Entretanto, os protestos não foram ainda maiores em vista das características locais de boa parte dos reassentados, que eram extremamente pobres, sem qualquer educação formal, temerosos e submissos ao governo (LIN, 2007).

Sobre a repressão do Estado frente aos protestos, Richard Louis Edmond argumenta que era uma estratégia do Partido Comunista para se evitar consequências políticas: "uma vez que o movimento ambiental tenha se estabelecido com sucesso para combater um problema, ele tende a ganhar impulso e muitas vezes torna-se foco de dissensão política" (EDMOND, 1994 apud BEATTIE, 2002, p. 148).

$\mathrm{Na}$ ausência de forte legislação ambiental e de poucas organizações nãogovernamentais capazes de articular esses descontentamentos, surgiram protestos individuais ou com pequeno número de envolvidos. Em 1992, foram presos 179 envolvidos em um protesto contra o reassentamento forçado. Outros episódios isolados e pontuais foram ocorrendo no início do projeto (LIN, 2007).

A aprovação do projeto e o início das obras no começo da década de 1990, possibilitam a percepção da necessidade de articulação de interesses da população, concomitantemente com uma atuação voltada para a preocupação ambiental. A Lei de Proteção Ambiental havia sido aprovada em 1989, mas ainda tinha uma aplicação limitada (FERREIRA, 2017). A controvérsia sobre o Projeto da Hidrelétrica das Três Gargantas gradualmente despertou o interesse público para questões ambientais e, concomitantemente com outros episódios (como pressão internacional, início da atuação de ONGs internacionais, Rio 92, etc.), criou condições para o surgimento de grupos defensores do meio ambiente (BARBIERI; FERREIRA, 2017).

A atuação de entidades organizadas passa a desempenhar um importante papel na arena política que se desenvolve na região das Três Gargantas. Questões sociais, de 
reassentamento, garantia de direitos humanos, preocupações com meio ambiente, passam a ter lugar na agenda política ao longo da década de 1990, quando muito lentamente o Estado se abre para essas atuações. O envolvimento em negociações internacionais na área ambiental fez a China almejar legitimidade social no campo ambiental, fortalecendo órgãos governamentais e tolerando maior atuação da sociedade civil, principalmente a partir do incentivo às GONGO's (Government Organized NonGovernment Organization), organização da sociedade civil parcialmente controlada pelo governo (FONSECA, 2013; BARBIERI; FERREIRA, 2017).

Essa atuação no caso das Três Gargantas refletiu diretamente quando se decidiu construir uma nova hidrelétrica no Rio $\mathrm{Nu}$, no início da década de 2000, conforme apresenta Igor Ferraz da Fonseca:

\begin{abstract}
Autores como Xie \& Heijden (2010) e Hensengerth (2010) apontam que o processo decisório relacionado à usina de três gargantas foi marcado por autoritarismo e repressão, onde contradições intragovernamentais não foram tornadas visíveis ao público e a sociedade civil contrária à usina sofreu repressão e não tinha canais para manifestação e participação no processo decisório. Já o caso do Nu River Project, reflete um momento no qual a legislação ambiental chinesa contempla um processo de licenciamento ambiental, conflitos intragovernamentais são visibilizados e a sociedade civil encontra formas de manifestação e influencia no processo decisório, permitidas por um governo que cada vez mais se preocupa com sua legitimidade e adere a pactos globais para a sustentabilidade ambiental. A mobilização contrária ao Nu River Project teve sucesso em frear - pelo menos por um breve período - a construção do complexo de hidrelétricas. (FONSECA, 2013, p. 10)
\end{abstract}

\title{
Considerações Finais
}

A grande pergunta que fica ao se analisar a implementação da hidrelétrica das Três Gargantas refere-se aos custos sociais e ambientais do projeto. Os benefícios resultantes da instalação da hidrelétrica são inegáveis: uma alta produção de energia elétrica, melhoria na navegação em vários trechos do rio, melhor controle das inundações, uma fonte alternativa ao carvão para produção de energia. Como não é possível colocar em 
uma balança o peso dos benefícios e dos impactos, o que se discute é o custo para a sociedade e o meio ambiente de uma grande obra como essa.

A instalação de hidrelétricas em diversos países do mundo traz à tona questionamentos como esse. A necessidade de se discutir produção energética é fundamental, pois diversificar a matriz, buscando fontes limpas e renováveis, principalmente a partir da energia solar e eólica é o grande ideal a ser atingido, entretanto, a produção por esses meios ainda está muito distante da demanda energética atual.

Espera-se que os investimentos em fontes alternativas criem novas tecnologias que permitam a produção diversificada e com menores impactos sociais e ambientais, permitindo a superação da produção baseada em combustíveis fósseis ou a partir de hidrelétricas e usinas nucleares, que hoje estão no centro da discussão energética em virtudes de aspectos sociais e ambientais.

Um novo momento na condução política da China é marcado pela incorporação da preocupação ambiental em suas decisões políticas, principalmente a partir do $13^{\circ}$ Plano Quinquenal, que orienta os esforços nacionais à construção de uma civilização ecológica, com altos investimentos em produção de energia eólica e solar, ambiental e socialmente responsáveis, minimizando os impactos e conflitos.

\section{Referências}

ALCÂNTARA JUNIOR, José. Georg Simmel e o Conflito Social. Caderno Pós Ciências Sociais, v. 2, n. 3, 2005.

BARBIERI, Mariana Delgado; FERREIRA, Leila C. Mudanças climáticas e governança multiatores na China contemporânea. Encontro da associação nacional de pesquisas de pós-graduação em ambiente e sociedade, Natal, 2017.

BASSO, Larissa; VIOLA, Eduardo. Chinese energy policy progress and challenges in the transition to low carbono development, 2006-2013. Revista Brasileira de Política Internacional, n. 57, 2014. 
BEATTIE, James. Dam Building, dissent, and development: the emergence of the Three Gorges Project. New Zealand Journal of Asian Studies, v.1, n.4, 2002.

BECK, U. Sociedade de risco: rumo a uma outra modernidade. São Paulo: Ed. 34, 2010.

CAMPBELL-HYDE, Blake. Breaking ground: environmental and social issues of the three Gorges Dam in China, 2011. Disponível em http://www1.american.edu/ted/ICE/china-damimpact.html acesso em 23 de junho de 2016.

CHINA. The 13th five-year plan for economic and social development of the people's Republic of China (2016-2020). Beijing: Central Compilation \& Translation Press, 2015.

DAVID, Marília Luz. Sobre os conceitos de risco em Luhmann e Giddens. Revista eletrônica dos Pós Graduandos em Sociologia Política UFSC, v. 8, n.1, 2011.

FERREIRA, Leila. C. e BARBI, F. Questões ambientais e prioridades políticas na China. ComCiência, v. 137, p. 01-05, 2012.

FERREIRA, Leila C.; BARBI, Fabiana; D'OTTAVIANO, Marília. Global environmental changes: environmental policies in China and Brazil. Tempo do Mundo, v. 2, n. 1, 2016.

FERREIRA, Leila C. (Org.). O desafio das mudanças climáticas: os casos Brasil e China. Jundiaí: Paco Editorial, 2017.

FONSECA, Igor Ferraz da. Licenciamento ambiental, conflitos socioambientais e coordenação intragovernamental: os casos da usina hidrelétricas de Belo Monte, no Brasil; do completo hidrelétrico do Rio Nu, na China; e da barragem de Sardar Sarovar, na Índia. Colóquio Internacional de Doutorandos/as do CES,4. 6-7 de dezembro, 2013.

GIDDENS, Anthony. As consequências da modernidade. São Paulo: Editora UNESP, 1991.

GIDDENS, Anthony. A política da mudança climática. Rio de Janeiro: Zahar, 2010.

GLEICK, Peter. Three Gorges Dam Project, Yangtze River, China. In: GLEICK, P. et al. The world's water 2008 - 2009. The biennial report on freshwater resources. London, 2009.

INTERNATIONAL RIVERS NETWORK. Human rights dammed off at Three Gorges. Report, 2003. Disponível em https://www.internationalrivers.org/files/attached-files/3gcolor.pdf. Acesso em: 14 junho de 2016. 
IPCC - INTERGOVERNMENTAL PANEL ON CLIMATE CHANGE. Climate change 2007: impacts, adaptation and vulnerability. Contribution of working group II to the fourth assessment report of the international panel on climate change'. Cambridge, Cambridge University Press. 2007.

IPCC - INTERGOVERNMENTAL PANEL ON CLIMATE CHANGE. Working Group I Contribution to the IPCC Fifth Assessment Report. Climate Change 2013: The Physical Science Basis. Summary for Policymakers. 2013.

LIANG, Jiaqi. The impacto of China's Three Gorges Project: an Evaluation of its effect on energy substitution and carbono dioxide reduction. The Public Purpose, v. 8, 2010.

LIMA, Erica N. O XI Plano Quinquenal Chinês - diminuindo as disparidades regionais. Monografia (Departamento de Ciências Econômicas) - Universidade Federal de Santa Catarina, 2007.

LIN, Teh-Chang. Environmental NGOs and the Anti-Dam Movements in China: A Social Movement with Chinese Characteristics. Issues \& Studies, n. 4, 2007.

LIU, Zhu. Emissions report 2015. Harvard Kennedy School, 2015.

LULL, James. A China ligada: televisão, reforma e resistência. Rio de Janeiro: Rio Fundo, 1992.

MAHER, Robert. Three Gorges Dam, Yangtze River, China. ENGR 125CS, 2010. Disponível em: http://www.montana.edu/rmaher/engr125_flo6/Three\%20Gorges\%20Dam.pdf. Acesso em: 23 de junho de 2016.

POMAR, Wladimir. A revolução chinesa. São Paulo: Ática, 2003.

SIMMEL, Georg. Sociologia. São Paulo: Ática, 1983.

SPENCER, Jonathan. Em busca da China moderna: quatro séculos de história. São Paulo: Companhia das Letras, 1995.

TEIXEIRA, Raquel O. Santos. Conflitos socioambientais no licenciamento da usina hidrelétrica de Murta: a luta pelo sentido e o destino do território no médio Jequitinhonha - MG. Monografia (Departamento de Sociologia e Antropologia) Universidade Federal de Minas Gerais, 2005.

VEIGA, Lilian B. Elabras, et al. UHEs na China: o caso Usina Hidrelétrica de Três Gargantas. Congresso Brasileiro de Energia, 16. 2015. 
VIOLA, E. A dinâmica das potências mundiais e o acordo de Copenhague. Boletim da sociedade brasileira de economia ecológica, n. 23, 2010.

WATSON, Sarah. Three Gorges Dam conflict: views and analysis. Columbia State University, 2008.

WINES, Michael. China admits problems with Three Gorges Dam. New York Times, May 19, 2011.

WINTER, D.D.; LEIGHTON, D.C. Structural Violence. In: CHRISTIE, D.J.; WAGNER, R.V.; WINTER, D.D. (eds). Peace, conflict and violence: peace psychology in the $21^{\text {st }}$ century. New York: Prentice-Hall, 2001.

YANG, Xiankun; LU, X. X. Ten years of the Three Gorges Dam: a call for policy overhaul.

Environmental Research Letters, n. 8, 2013. 